\title{
Transfer of newly acquired stimulus valence between identities in dissociative identity disorder (DID).
}

Citation for published version (APA):

Huntjens, R. J. C., Peters, M. L., Postma, A., Woertman, L., Effting, M., \& van der Hart, O. (2005).

Transfer of newly acquired stimulus valence between identities in dissociative identity disorder (DID). Behaviour Research and Therapy, 43(2), 243-255. https://doi.org/10.1016/j.brat.2004.01.007

Document status and date:

Published: 01/01/2005

DOI:

10.1016/j.brat.2004.01.007

Document Version:

Publisher's PDF, also known as Version of record

Document license:

Taverne

\section{Please check the document version of this publication:}

- A submitted manuscript is the version of the article upon submission and before peer-review. There can be important differences between the submitted version and the official published version of record.

People interested in the research are advised to contact the author for the final version of the publication, or visit the DOI to the publisher's website.

- The final author version and the galley proof are versions of the publication after peer review.

- The final published version features the final layout of the paper including the volume, issue and page numbers.

Link to publication

\footnotetext{
General rights rights.

- You may freely distribute the URL identifying the publication in the public portal. please follow below link for the End User Agreement:

www.umlib.nl/taverne-license

Take down policy

If you believe that this document breaches copyright please contact us at:

repository@maastrichtuniversity.nl

providing details and we will investigate your claim.
}

Copyright and moral rights for the publications made accessible in the public portal are retained by the authors and/or other copyright owners and it is a condition of accessing publications that users recognise and abide by the legal requirements associated with these

- Users may download and print one copy of any publication from the public portal for the purpose of private study or research.

- You may not further distribute the material or use it for any profit-making activity or commercial gain

If the publication is distributed under the terms of Article $25 \mathrm{fa}$ of the Dutch Copyright Act, indicated by the "Taverne" license above, 


\title{
Transfer of newly acquired stimulus valence between identities in dissociative identity disorder (DID)
}

\author{
Rafaële J.C. Huntjens ${ }^{\mathrm{a}, *}$, Madelon L. Peters ${ }^{\mathrm{c}}$, Albert Postma ${ }^{\mathrm{b}}$, \\ Liesbeth Woertman ${ }^{\mathrm{a}}$, Marieke Effting ${ }^{\mathrm{a}}$, Onno van der Hart ${ }^{\mathrm{a}}$ \\ ${ }^{a}$ Department of Clinical Psychology, Faculty of Social Sciences, Utrecht University, P.O. Box 80.140, Utrecht 3508 TC, \\ The Netherlands \\ ${ }^{\mathrm{b}}$ Psychological Laboratory, Utrecht University, Utrecht, The Netherlands \\ ${ }^{\mathrm{c}}$ Department of Clinical, Medical, and Experimental Psychology, Maastricht University, Maastricht, The Netherlands
}

Received 29 April 2003; received in revised form 22 December 2003; accepted 20 January 2004

\begin{abstract}
Patients with Dissociative Identity Disorder (DID) frequently report episodes of interidentity amnesia, that is amnesia for events experienced by other identities. The goal of the present experiment was to test the implicit transfer of trauma-related information between identities in DID. We hypothesized that whereas declarative information may transfer from one identity to another, the emotional connotation of the memory may be dissociated, especially in the case of negative, trauma-related emotional valence. An evaluative conditioning procedure was combined with an affective priming procedure, both performed by different identities. In the evaluative conditioning procedure, previously neutral stimuli come to refer to a negative or positive connotation. The affective priming procedure was used to test the transfer of this acquired valence to an identity reporting interidentity amnesia. Results indicated activation of stimulus valence in the affective priming task, that is transfer of emotional material between identities.

(C) 2004 Elsevier Ltd. All rights reserved.
\end{abstract}

Keywords: Evaluative conditioning; Affective priming; Dissociative Identity Disorder

\footnotetext{
${ }^{*}$ Corresponding author. Tel.: + 31-30-253-1632; fax: +31-30-253-4718.

E-mail address: r.huntjens@fss.uu.nl (R.J.C. Huntjens).
} 


\section{Introduction}

Dissociative Identity Disorder (DID) is a psychiatric disorder that is described in the Diagnostic and Statistical Manual of Mental Disorders (4th ed., American Psychiatric Association, 1994) as involving the presence of two or more distinct identities or personality states, each with its own relatively enduring pattern of perceiving, relating to, and thinking about the environment and the self. The disorder is believed to originate from a self-protecting reaction to severe childhood abuse, which the child cannot escape from, nor can control or predict (e.g., Putnam, 1997; Ross, 1997). Essentially, DID is thought to involve the split between identities in which patients experience trauma over and over again and identities in which they experience partial or total amnesia for the abuse (cf., Nijenhuis \& Van der Hart, 1999). The extent to which the personality becomes fragmented into more identities depends on the severity of the traumatization in terms of developmental age at trauma onset, chronicity and intensity of the traumatization, and factors such as the relationship to the perpetrator and lack of support and social recognition of the trauma (Nijenhuis, Van der Hart, \& Steele, 2002).

In adult DID patients, reports of amnesia between identities generally not only include amnesia for traumatic events, but also pertain to daily experiences varying from amnesia for specific events to amnesia for all events experienced by other identities. The number of experimental studies on these reported memory problems is very limited (Allen \& Movius, 2000; Dick-Barnes, Nelson, \& Aine, 1987; Eich, Macaulay, Loewenstein, \& Dihle, 1997a, b; Ludwig, Brandsma, Wilbur, Benfeldt, \& Jameson, 1972; Nissen, Ross, Willingham, Mackenzie, \& Schacter, 1988; Peters, Uyterlinde, Consemulder, \& Van der Hart, 1998; Silberman, Putnam, Weingartner, Braun, \& Post, 1985; for reviews see Allen \& Movius, 2000; Dorahy, 2001) and besides, only neutral stimulus material has been included. Results of previous studies were interpreted by Nissen et al. (1988) and Eich, Macaulay, Loewenstein, and Dihle (1997a) as indicating interidentity amnesia on explicit memory tasks and on conceptual priming tasks, and interidentity transfer of information on perceptual priming tasks. However, in a more recent study on memory functioning in DID, with a relatively large patient sample $(n=31)$, we found that patients did show evidence of interidentity memory transfer equal to controls on explicit memory and conceptual priming tasks as well as on perceptual priming tasks, in contrast to patients' subjective reports of interidentity amnesia. In contrast to previous studies, much emphasis was placed in these experiments on providing objective measures of memory functioning in DID, that is not tapping patients' subjective beliefs of amnesia, but objective memory performance, by including memory tasks on which simulation was considered to be very difficult, and this was checked by the inclusion of a control group instructed to simulate DID. Explicit memory performance was tested in an interference paradigm (Huntjens, Postma, Peters, Woertman, \& Van der Hart, 2003), and implicit memory performance was tested by using speeded priming tasks (Huntjens et al., 2002).

The results of transfer of information between identities found in these experiments argue against the conclusion drawn by Nissen et al. (1988) and Eich et al. (1997a), and instead suggest that interidentity amnesia for neutral material may not be characteristic of DID memory functioning. The findings do not rule out, however, the possibility of interidentity amnesia for other, that is non-neutral, information. Given the fact that dissociation is supposed to serve as a self-protective reaction to overwhelming traumatic experiences to ward off intense emotional feelings with which the individual cannot cope, interidentity amnesia can be expected to occur 
especially for negative emotional stimuli, and in particular trauma-related stimuli. To test this assumption, we designed a second study $(n=22)$. To test explicit memory transfer, we again used an interference paradigm. As with neutral material, however, we found no objective evidence for interidentity amnesia, although patients subjectively reported complete interidentity amnesia for the material studied (Huntjens, Postma, Peters, Woertman, \& van der Hart, submitted).

The present experiment, also part of our second study into amnesia for trauma-related material in DID, focuses on implicit memory transfer for trauma stimuli between identities. It may be proposed that interidentity amnesia does not pertain so much to the content of material, but more to its associated emotional valence. Thus, whereas declarative information may transfer from one identity to another, the associated emotional connotation of the memory may be dissociated, especially in the case of negative, trauma-related emotional valence. In other words, we argue that patients may retrieve trauma-related material in a detached way in amnesic identities, while experiencing (the full) emotional quality in non-amnesic identities.

Following De Houwer, Hermans, and Eelen (1998), the experiment consisted of two phases, a learning phase consisting of an evaluative conditioning procedure, and a test phase, consisting of an affective priming procedure. The two phases were performed by different identities. In order to establish an amnesic barrier for the emotional- or more specifically trauma-related-valence of the words, it was essential that stimuli with a neutral emotional connotation were used that newly acquired their emotional valence, as existing emotional material may already have a different valence in the different identity states.

In the first phase, stimuli that were originally neutral were given an emotional connotation by repeatedly pairing them with distinctly negative, that is trauma-related, and positive words. The term evaluative conditioning refers to the observation that the mere spatio-temporal cooccurrence of a neutral stimulus $\mathrm{X}$ with a valenced stimulus $\mathrm{Y}$ may result in the originally neutral stimulus $\mathrm{X}$ itself acquiring an evaluative meaning that is congruent with the valence of $\mathrm{Y}$. The acquired valence is not subject to extinction, as is the case in classical conditioning procedures (Hermans, Baeyens, \& Eelen, in press). Nonwords (e.g., BAYRAM) served as neutral stimuli X and existing positive, negative, and neutral words served as valenced stimuli $\mathrm{Y}$. The negatively valenced stimuli were chosen to refer to traumatic experiences of sexual or physical abuse and emotional neglect reported by DID patients.

Next, it was tested whether this newly acquired emotional valence transferred form one identity to another identity reporting amnesia for the learning phase. In priming studies, the effect of one stimulus (the prime) on the processing of a second stimulus (the target) is determined (De Houwer et al., 1998). In affective priming, the priming effect of an affective association between prime and target is examined. Responses to target words are facilitated if both prime and target have the same valence, and inhibited if they are of opposite valence, as compared to the control trials, which consist of trials using primes with neutral valence. The affective priming procedure thus indexes the stimulus valence that is acquired by prior evaluative learning (see also Glautier \& De Houwer, 2000; Hermans, Baeyens, \& Eelen, 2003; Hermans, Baeyens, Lamote, \& 2000). The nonwords with newly acquired emotional valence served as primes and the existing positive and trauma-related words used in the learning phase as the targets. In the priming phase, there were four possible relations between the nonword (prime) and the word (target): (1) the target could have been associated with the prime in the learning phase (identity congruent); (2) the target could have the same affective connotation as the existing word that was associated with the prime in the 
learning phase (affectively congruent); (3) the target could have a different affective connotation than the existing word that was associated with the prime during the learning phase (incongruent); (4) the prime could have been paired with a neutral existing word in the conditioning phase and thereby acting as a control trial in the priming phase. Affective priming is demonstrated when response times on affectively congruent trials are faster than on incongruent trials. The term "episodic identity priming" is preserved for faster responses in trials when a nonword precedes the specific word with which it was associated during the learning phase, that is faster response times on identity congruent trials than on affectively congruent trials. If patients are amnesic not for the declarative content but for the emotional content of the material, trauma-related primes should be processed as neutrally valenced, that is no facilitation or inhibition in target categorization for trials with trauma-related primes is expected. In other words, patients are expected to show a preserved episodic identity priming effect while lacking an affective priming effect.

We included a control group matched on age and education. Moreover, we included a second control group instructed to simulate DID. Affective priming is supposed to be an automatic process in the sense that it can occur independently of an evaluative intention and of awareness of the instigating stimulus (e.g. Hermans, De Houwer, \& Eelen, 2001). Consequently, affective priming is not (easily) influenced by demand effects and response strategies. This makes it a suitable procedure in situations were demand effects might otherwise influence responding (Hermans, Spruyt, \& Eelen, 2003). The simulators were included to ascertain that participants were indeed unable to actively suppress the priming effect.

\section{Method}

\subsection{Participants}

Twenty-two female DID patients participated. They were recruited in 18 treatment settings in the Netherlands and Belgium by asking clinicians to invite patients to participate. Nine patients also participated in our previous study on interidentity amnesia. Conditions for participation were described as follows: (1) The DID diagnosis was made by referring clinician by administration of the Structured Clinical Interview for DSM-IV Dissociative Disorders (SCID-D; Steinberg, 1993; Dutch version validated by Boon and Draijer, 1993); (2) at least one of the identities report a complete amnesia for the events experienced by the other participating identity during the experiment; (3) identities are able to perform the tasks without interference of other identities; (4) they are able to perform the tasks without spontaneous switches to other identities; (5) they are all able to switch between identities on request. Patients self-selected two identities that would participate in the experiment. The mean number of years since diagnosis of DID for patients in the present study was 6 years and DID was always the main reason for patients to be in treatment. Twelve patients reported one or more prior diagnoses: major depressive disorder $(n=6)$, borderline personality disorder $(n=4)$, posttraumatic stress disorder $(n=3)$, anorexia nervosa $(n=3)$, schizophrenia $(n=3)$, dissociative disorder not otherwise specified $(n=2)$, epilepsy $(n=1)$, obsessive compulsive disorder $(n=1)$, personality disorder not otherwise specified $(n=1)$, bipolar disorder $(n=1)$, and avoidant personality disorder $(n=1)$. Seven patients reported present comorbid disorders: major depressive disorder $(n=2)$, posttraumatic stress 
disorder $(n=2)$, anorexia nervosa $(n=1)$, obsessive compulsive disorder $(n=1)$, bipolar disorder $(n=1)$, personality disorder not otherwise specified $(n=1)$, and avoidant personality disorder $(n=1)$.

In addition, 50 female non-psychiatric control participants participated. They were community volunteers and received a small payment. They did not report any relevant memory, visual, attentional problems or psychiatric disorders and no history of sexual abuse. Control participants were assigned randomly to either a control group or a simulating group. Groups were matched as closely as possible on age $(M=39.95, \mathrm{SD}=8.81$ for patients $(n=22), M=36.48, \mathrm{SD}=8.17$ for normal controls $(n=25)$, and $M=36.72, \mathrm{SD}=7.88$ for simulators $(n=25))$ and education, which was assessed in categories ranging from 1 (low) to 7 (high) (Verhage, 1964), $(M=5.36$, $\mathrm{SD}=1.59$ for patients, $M=5.76, \mathrm{SD}=1.13$ for normal controls, and $M=5.68, \mathrm{SD}=1.18$ for simulators). Participants in the simulating group were instructed to mimic DID. They were shown a documentary about a DID-patient and were given additional written information about DID. They were subsequently asked to make up an imaginary, amnesic identity and come up with detailed characteristics of this identity. Following Silberman et al. (1985) procedure, they were given a 17-item data sheet for the identity on which they were asked to assign name, age, sex, physical description, personal history, and personality style. Examination of the completed data sheets confirmed that participants had spent considerable effort into inventing an identity. Finally, they were asked to practice during the week preceding the test in switching to their "identity" and taking on its state of mind. Participants in the normal control group were only told that they participated in a memory experiment. No information was provided on the DID related aspects of the study.

All participants completed both the Dissociative Experiences Scale (DES; Carlson \& Putnam, 1993) and the Creative Experience Questionnaire (CEQ; Merckelbach, Rassin, \& Muris, 2000). The DES is a 28-item self-report questionnaire with scores ranging from 0 to 100 . Scores above 20, or more conservatively, above 30 are thought to be indicative of pathological dissociation (Carlson \& Putnam, 1993). The CEQ is a Dutch 25-item self-report questionnaire with scores ranging from 0 to 25 . High scores are thought to be indicative of "fantasy proneness", that is the inclination to be immersed in daydreams and fantasies. Mean scores on the DES were $M=52.19$ $(\mathrm{SD}=16.41)$ for patients $(n=22), M=9.81(\mathrm{SD}=8.11)$ for normal controls, and $M=8.11$ $(\mathrm{SD}=4.71)$ for simulators. Scores on the CEQ were $M=9.70(\mathrm{SD}=4.50)$ for patients $(n=22)$, $M=6.52(\mathrm{SD}=3.29)$ for normal controls, and $M=6.64(\mathrm{SD}=4.02)$ for simulators. Control participants did thus not show a pathological level of dissociation as measured by the DES. The normal control group and the simulating control group did not differ significantly on DES, $t(48)=.91, p=.37$. They also did not differ significantly on CEQ, $t(48)=-.12, p=.91$. Patients on the other hand differed significantly from normal controls both on the DES, $t(45)=11.44$, $p<.01$, and the CEQ, $t(45)=2.79, p=.01$. Written informed consent was obtained from patients as well as all control participants prior to participation.

\subsection{Materials}

The material in the evaluative conditioning task and the affective priming task consisted of 10 Turkish words (e.g., BAYRAM) and 10 Dutch words. The Turkish words were unknown to the participants and thus can be regarded as nonwords. They were selected from the materials used by 
Yazuv (1963) and were also used in a study by De Houwer et al. (1998). Of the Dutch words, four were trauma-related (RAPE, FEAR, KNIVES, and INCEST), four were positive (PEACE, HUMOR, RAINBOW, and BEAUTY), and two were neutral (MOTOR-BUS and SOCCER). They were selected from a study performed by Hermans and De Houwer (1994), in which affective and subjective familiarity ratings of 740 Dutch words were determined on seven-point visual analogue scales. Scales ranged from negative (1) to positive (7) and from unfamiliar (1) to familiar (7). The mean affective rating for the trauma-related words was 1.82 , for the positive words 6.11 , and for the neutral words, 3.84. The mean subjective familiarity rating for the trauma-related words was 4.36, for the positive words 4.95, and for the neutral words, 4.84. The mean word length for the trauma-related words was 7.25, for the positive words 7.25 , and for the neutral words, 7.00. All words and nonwords were presented in white uppercase letters.

\subsection{Procedure}

The experiment consisted of an evaluative conditioning phase and an affective priming phase, performed by different identities. The evaluative conditioning phase consisted of an evaluative rating task, an evaluative conditioning task, a cued recall task, and a second evaluative rating task. In the first evaluative rating phase, the participants rated words on valence to provide a base rating. All 20 (nonwords as well as existing words) words were rated on a paper-and-pencil version of the Self-Assessment Manikin (SAM, see Bradley, Greenwald, Petry, \& Lang, 1992), used to rate affective valence. The scale ranges from 1 (happy/positive) to 9 (unhappy/negative).

In the evaluative conditioning task, nonword-word pairs were learned. Participants were told that words from a non-Dutch language would be presented together with their Dutch translations, and they were instructed to memorize the translation of each word. They were told that we wanted to investigate how fast they could learn the meaning of non-Dutch words. For each participant, the computer program randomly assigned each nonword to a different (trauma-related, positive, or neutral) Dutch word. All resulting 10 nonword-word pairs were then presented six times in a randomized order. Each subject received a different randomized order. Also, the presentation of a pair could only be repeated after all other pairs had been presented for an equal number of times. On each trial, a dash was presented in the middle of the screen together with a nonword that was located at the left side of the dash. After $1 \mathrm{~s}$, the so-called translation appeared on the right side of the dash. The word and nonword were presented together for $5 \mathrm{~s}$. The inter-trial interval was $3 \mathrm{~s}$.

When all pairs were presented six times, a cued recall test was administered in order to see how well participants had learned the pairs. On each trial, a nonword was presented in the middle of the screen and participants were instructed to try to recall the correct translation and write it down. If they could not remember the correct translation, they had the opportunity to guess but could also proceed without giving a response. The next word appeared after $3 \mathrm{~s}$ after a response had been entered. Nonwords were presented in a randomly determined order.

In the second evaluative rating phase, the participants again rated the words on valence using the Self-Assessment Manikin to provide an index of evaluative conditioning.

In the affective priming phase, the nonwords served as primes and the trauma-related words and positive words served as targets. The neutral words did not appear in the priming phase. On each trial, a nonword was presented, followed by an existing word with a positive or negative 
affective connotation. The task consisted of naming the affective connotation of the existing word as fast as possible. For half of the subjects, the m-key on the keyboard was the "NEGATIVE" key and the z-key was the "POSITIVE" key. For the other half, the correspondence between key and response was reversed. We stressed that the existing word was important and that the nonDutch word was added to make the task resemble conditions in normal text reading. Participants were asked not to divert their eyes from the presentation of the prime.

The priming phase consisted of two blocks of 80 trials, that is 32 affectively congruent trials (of which 8 identity congruent), 32 incongruent trials, and 16 control trials. A brief break appeared after the first block of 80 trials. Presentation order was randomized separately for each participant. A trial consisted of the following sequence: a fixation cross $(500 \mathrm{~ms})$, a blank screen ( $200 \mathrm{~ms}$ ), the prime for $200 \mathrm{~ms}$, and the target. The delay between the onset of the prime and target (stimulus onset asynchrony; SOA) thus was $200 \mathrm{~ms}$. The target was presented until a response was registered. Both stimuli were presented in the center of the screen. The intertrial interval was $2 \mathrm{~s}$.

Patients were asked to switch between identities between the evaluative conditioning phase and the test phase. The transition was initiated by asking the patient to let an identity "come forward" and take control over the patient's consciousness and behavior. Also, the patient was asked to let the other participating identity "step back" and move out of consciousness. The switching process was assisted either by the patients' own clinician or by one of the authors (RH or OvdH). The switching process was always accomplished in less than $2 \mathrm{~min}$.

Participants in the simulating control group performed the evaluative conditioning phase while being in their normal identity state and the affective priming after having "switched" to their imagined "amnesic" identity. Before "switching" to their other identity, they were instructed to pretend that they did not know their normal identity had seen foreign words and their translation. They were also asked not to respond faster to Dutch words when it was preceded by its translation, while still trying to respond as fast as possible. Subsequently, they were given 2 min to take on the other identity's state of mind. Participants in the control group performed the task without switching. Instead, they had a 2-min break to keep the length of procedures equal between groups. The experiment described was part of a larger investigation on memory (dis)abilities in DID.

\section{Results}

Of the 22 DID patients tested, one patient reported, after her switch to identity 2 , knowledge of the learning phase. This patient was not included. Two patients did not complete the tasks because the procedure proved too taxing for them. The data thus pertain to 19 DID patients who subjectively reported complete one-way amnesia for the learning phase including the words presented. An alpha level of .05 was used for all statistical tests and all tests described were twotailed. All multiple comparisons procedures described were Bonferroni tests.

\subsection{Cued recall}

Patients correctly recalled $74 \%$ of the trauma-related word-nonword pairs, $71 \%$ of the positive word-nonword pairs, and $82 \%$ of the neutral word-nonword pairs. Normal controls recalled 
$83 \%$ of the trauma-related word-nonword pairs, $86 \%$ of the positive word-nonword pairs, and $90 \%$ of the neutral word-nonword pairs, compared to simulating controls recalling $91 \%$ of the trauma-related word-nonword pairs, $82 \%$ of the positive word-nonword pairs, and $92 \%$ of the neutral word-nonword pairs. Analysis was accomplished by repeated measures analysis of variance with Word Category [trauma-related, positive, neutral] as within-subjects factor, and Diagnosis [patients, controls and simulators] as between-subjects factor. The analysis revealed a significant Word Category main effect, $F(2,65)=3.76, p=.03$, reflecting a significant higher neutral word recall when compared to positive words, $F(1,66)=7.48, p=.01$. The Diagnosis Group main effect was not significant, $F(2,66)=1.75, p=.18$, and neither was the Diagnosis Group $\times$ Word Category interaction, $F(4,132)=.94, p=.45$.

\subsection{Manipulation check}

Mean patient base ratings on the SAM of existing words were $8.34(\mathrm{SD}=.91)$ for trauma-related words, $2.82(\mathrm{SD}=1.60)$ for positive words, and $5.03(\mathrm{SD}=1.42)$ for neutral words. Normal controls' mean ratings were $8.13(\mathrm{SD}=1.07)$ for trauma-related words, $1.84(\mathrm{SD}=1.15)$ for positive words, and $4.72(\mathrm{SD}=1.60)$ for neutral words. Simulating controls' mean ratings were 8.29 $(\mathrm{SD}=.75)$ for trauma-related words, $1.76(\mathrm{SD}=.69)$ for positive words, and $5.34(\mathrm{SD}=1.40)$ for neutral words. An analysis of variance revealed a significant main effect of Word Category, $F(2,65)=407.30, p<.01$. Within-subjects contrasts indicated that trauma-related words were rated significantly more negative/unhappy than positive words, $F(1,66)=820.09, p<.01$, and neutral words, $F(1,66)=207.55, p<.01$. Positive words were rated more positive/happy than neutral words, $F(1,66)=206.81, \quad p<.01$. The Diagnosis main effect did marginally reach significance, $F(2,66)=3.09, p=.05$, with patients rating words more negative/unhappy than normal controls, $p=.05$. The Word Category $\times$ Diagnosis interaction was not significant $F(4,132)=2.02, p=.10$.

\subsection{Evaluative conditioning}

Participants' mean base ratings of nonwords on the SAM and mean ratings in the second rating, after nonwords had been paired with existing words, are presented in Table 1. An ANOVA on the base ratings of the nonwords revealed that Diagnosis groups did not differ significantly in base ratings, $F(2,66)=.84 p=.43$. A repeated measures of variance on the second ratings indicated a significant main effect for Word Category, $F(2,65)=81.17, p<.01$. Within-subjects contrasts revealed that trauma-related words differed significantly from positive words, $F(1,66)=156.52, p<.01$, and from neutral words, $F(1,66)=101.47, p<.01$. Positive words also differed significantly from neutral words, $F(1,66)=42.18, p<.01$. This effect did not differ between diagnosis groups, $F(4,132)=.07, p=.99$. Also, the Diagnosis main effect was not significant, $F(2,66)=1.18, p=.31$. Evaluative conditioning thus seemed successful to an equal degree in DID patients, normal controls and simulators.

\subsection{Affective priming}

Mean errors on identity congruent, affective congruent, incongruent, and control trials differed between $5 \%$ and $9 \%$ for patients, between $3 \%$ and $7 \%$ for controls, and between $2 \%$ and $4 \%$ for 
simulators. An analysis of variance yielded no significant main or interaction effects, except for a significant Diagnosis main effect, $F(2,66)=4.81, p=.01$, with multiple comparisons showing that patients made significantly more errors than simulators, $p=.01$, but not significant more errors than normal controls, $p=.56$. Simulators also did not differ significantly from normal controls, $p=.20$.

In calculating mean response times, we excluded incorrect responses and response times below $250 \mathrm{~ms}$ and response times that were three or more standard deviations from the mean per item and per participant from the data analyses. Mean response times can be found in Table 2. A repeated measures analysis of variance on mean response times showed a significant congruence effect, $F(3,64)=7.87, p<.01$. Within-subjects contrasts showed that identity congruent trials differed significantly from affective congruent trials, $F(1,66)=4.38, p=.04$, and that affective congruent trials differed significantly from incongruent trials, $F(1,66)=6.26, p=.02$. Incongruent trials did not differ significantly from control trials, $F(1,66)=.39, p=.54$. Affective congruent trials did differ significantly from control trials, $F(1,66)=4.49, p=.04$.

Most importantly, the three-way interaction Congruence $\times$ Valence $\times$ Diagnosis was far from significant, $F(6,130)=1.17, p=.33$, indicating patients did not show a trauma-related specific lack of affective priming, which would be expected in case of interidentity amnesia for emotional

Table 1

Evaluative conditioning: SAM (Self-Assessment Manikin) ratings (SD) for Nonwords for DID Patients $(n=19)$, Controls $(n=25)$, and simulators $(n=25)$

\begin{tabular}{llll}
\hline & DID Patients & Controls & Simulators \\
\hline First rating & $5.29(.60)$ & $5.25(.86)$ & $5.04(.58)$ \\
Second rating & & & \\
Paired with trauma-related words & $7.53(1.66)$ & $7.11(1.29)$ & $7.37(1.31)$ \\
Paired with positive words & $3.57(2.26)$ & $3.23(1.46)$ & $3.27(1.66)$ \\
Paired with neutral words & $5.29(1.73)$ & $4.78(1.25)$ & $4.88(1.56)$ \\
\hline
\end{tabular}

Table 2

Mean response times (SD) for trauma-related and positive identity congruent, affective congruent, incongruent, and control trials for DID patients $(n=19)$, Controls $(n=25)$, and Simulators $(n=25)$

\begin{tabular}{llll}
\hline & DID patients & Controls & Simulators \\
\hline Trauma-related & & & \\
Identity congruent trials & $725(142)$ & $558(71)$ & $610(94)$ \\
Affective congruent trials & $739(137)$ & $576(68)$ & $625(97)$ \\
Incongruent trials & $744(124)$ & $588(65)$ & $628(95)$ \\
Control trials & $755(142)$ & $588(66)$ & $630(96)$ \\
Positive & & & $614(118)$ \\
Identity congruent trials & $747(182)$ & $573(79)$ & $620(95)$ \\
Affective congruent trials & $770(158)$ & $570(75)$ & $631(98)$ \\
Incongruent trials & $779(160)$ & $579(68)$ & $631(107)$ \\
Control trials & $753(155)$ & $581(68)$ & \\
\hline
\end{tabular}


valence for trauma-related material. Also, the two-way interaction Congruence $\times$ Diagnosis proved nonsignificant, $F(6,130)=.53, p=.79$, indicated that the pattern of congruence did not differ between diagnosis groups, although response times show a normal controls' lack of episodic identity priming for positive trials.

A nonsignificant interaction Congruence $\times$ Valence, $F(3,64)=1.18, p=.33$, indicated the congruence effect did not differ between trauma-related and positive trials. Also, the Valence main effect was not significant, $F(1,66)=1.53, p=.22$, and neither was the Valence $\times$ Diagnosis interaction, $F(2,66)=1.53, p=.22$.

Again, we found a significant Diagnosis Group effect, $F(2,66)=16.91, p<.01$. A multiple comparisons procedure indicated DID patients were significantly slower than normal controls, $p<.01$, and simulators, $p<.01$. Normal controls did not differ significantly in mean reaction time from simulators, $p=.31$.

\section{Discussion}

The neutral ratings on the self-assessment manikin (SAM) showed that the Turkish words used as neutrally valenced nonwords could indeed be regarded as such. Furthermore, we can conclude that the nonwords, while initially being rated as neutral by all diagnosis groups, acquired the valence of the trauma-related and positive words they were paired with in the cued recall task, as is evident from their significant different positive and negative ratings on the SAM in the second rating. There was no difference in ratings in the second rating between diagnosis groups, so evaluative conditioning proved successful to an equal degree in both control groups as well as in DID patients. Also, participants did not differ in cued recall of the 'meaning' of the nonwords.

Crucial for the phenomenon of interidentity amnesia in DID was the word categorization task performed in the affective priming phase that was used to determine the transfer of the newly acquired valence between identities. All subjects showed evidence of a significant episodic priming effect for trauma-related material, and patients as well as simulating controls revealed of a significant episodic priming effect for positive material, as is evident from their faster responses on identity congruent trials compared to their responses on affective congruent trials. All subjects had an affective priming effect for both trauma-related as well as positive words, as is evident from their faster responses on affectively congruent trials compared to their responses on incongruent trials. In the patient group, one patient reported knowledge of the learning phase, after her switch to identity 2. All patients, but one, reported a complete amnesia for the words learned in the evaluative conditioning phase. In case of amnesia for the trauma-related content of the material, we expected trauma-related primes to be processed as neutrally valenced, that is no facilitation or inhibition in target categorization for trials with trauma-related primes. We found patients, however, not to differ significantly from normal controls and simulating controls in the congruence effect. The experiment thus shows evidence of patients' transfer of declarative content, as evidenced by an identity priming effect, as well as of emotional connotation, as indicated by an affective priming effect, of trauma-related words between identities. Thus, in contrast to patients' reports, we found evidence of intact memory functioning in DID.

Several differences between our study and the De Houwer et al. (1998) study may be noted. De Houwer et al. found that responses were significantly faster to positively valenced targets compared 
to negatively valenced targets. The positive and negative targets used in that study were, however, not matched on word frequency and they argued this might have caused the difference in response times. In the present experiment, positive and negative target words were matched on frequency, subjective familiarity, as well as on word length. We did not find a significant valence effect in word categorization, confirming their reasoning that incomparability of stimuli rather than word valence caused the faster responses to positive targets found in their study. Other additions to the procedure used by De Houwer et al. (1998) were the inclusion of pre- and post-learning evaluative rating tasks to measure evaluative conditioning and the inclusion of neutral words in the cued recall task to generate neutrally valenced nonwords as control primes in the affective priming task. We did not find a significant difference between incongruent trials and control trials, thus no significant evidence of inhibition in target categorization, but we did find a significant difference between affective congruent trials and control trials, reflecting facilitation in categorization.

In conclusion, not only the declarative content of the stimulus material transferred between identities, but also stimulus valence newly acquired by one identity transferred to another, amnesic identity, as evidenced by the presence of an affective priming effect. This occurred for both positive as well as negative, trauma-related, emotional valence. The results thus indicate transfer of trauma material between identities. Combining these results with previous observations of explicit and implicit memory transfer of neutral material (Allen \& Movius, 2000; Eich et al., 1997b; Huntjens et al., 2002, 2003; Silberman et al., 1985), and explicit memory transfer of trauma-related material (Huntjens et al., submitted), it can be concluded that amnesia does not seem to be an inherent characteristic of memory functioning in DID. While patients subjective report fragmentation of memory in separate identities, the results of objective memory testing argue against the existence of amnesic barriers in DID.

\section{Acknowledgement}

Albert Postma was supported by a grant from the Netherlands Organization for Fundamental Research (NWO, No. 440-20-000).

We thank Erno Hermans, Jan de Houwer, Dirk Hermans, Frank Baeyens, Peter de Jong, and Edith Schlösser-Plum for their help in designing the study. We especially thank the patients who participated in the study and the clinicians for their help in gathering the patient sample and for their assistance in testing.

\section{References}

Allen, J. B., \& Movius, H. L. (2000). The objective assessment of amnesia in dissociative identity disorder using eventrelated potentials. International Journal of Psychophysiology, 38, 21-41.

American Psychiatric Association (1994). Diagnostic and statistical manual of mental disorders (4th ed.). Washington, DC: Author.

Boon, S., \& Draijer, N. (1993). Multiple personality disorder in the Netherlands: A study on reliability and validity of the diagnosis. Lisse, The Netherlands: Swets \& Zeitlinger.

Bradley, M. M., Greenwald, M. K., Petry, M. C., \& Lang, P. J. (1992). Remembering pictures: Pleasure and arousal in memory. Journal of Experimental Psychology: Learning, Memory, and Cognition, 18, 379-390. 
Carlson, E. B., \& Putnam, F. W. (1993). An update on the dissociative experiences scale. Dissociation, 6, 16-27.

De Houwer, J., Hermans, D., \& Eelen, P. (1998). Affective and identity priming with episodically associated stimuli. Cognition and Emotion, 12, 145-169.

Dick-Barnes, M., Nelson, R. O., \& Aine, C. J. (1987). Behavioral measures of multiple personality: The case of Margaret. Journal of Behavioral Therapy and Experimental Psychiatry, 18, 229-239.

Dorahy, M. J. (2001). Dissociative identity disorder and memory dysfunction: The current state of experimental research, and its future directions. Clinical Psychology Review, 21, 771-795.

Eich, E., Macaulay, D., Loewenstein, R. J., \& Dihle, P. H. (1997a). Memory, amnesia, and dissociative identity disorder. Psychological Science, 8, 417-422.

Eich, E., Macaulay, D., Loewenstein, R. J., \& Dihle, P. H. (1997b). Implicit memory interpersonality amnesia and dissociative identity disorder Comparing patients with simulators. In J. D. Read, \& D. S. Lindsay (Eds.), Recollections of trauma scientific research and clinical practice (pp. 469-474). New York: Plenum Press.

Glautier, S. \& De Houwer, J. (2000). Classical conditioning of facial electromyographic and affective responses using emotionally significant visual images as unconditioned stimuli. Manuscript submitted for publication.

Hermans, D., Baeyens, F., \& Lamote, S. (2000). Evaluative conditioning of brand CS with odor US: A demonstration using the affective priming technique. Manuscript in preparation.

Hermans, D., Baeyens, F., \& Eelen, P. (2003). On the acquisition and activation of evaluative information in memory: The study of evaluative learning and affective priming combined. In J. Musch, \& K. C. Klauer (Eds.), The psychology of evaluation (pp. 139-168). Mahwah, NJ: Lawrence Erlbaum.

Hermans, D., \& De Houwer, J. (1994). Affective and subjective familiarity ratings of 740 Dutch words. Psychologica Belgica, 34, 115-139.

Hermans, D., De Houwer, J., \& Eelen, P. (2001). A time course analysis of the affective priming effect. Cognition and Emotion, 15, 143-165.

Hermans, D., Spruyt, A., \& Eelen, P. (2003). Automatic affective priming of recently acquired stimulus valence: Priming at SOA 300 but not at SOA 1000. Cognition and Emotion, 17, 83-99.

Huntjens, R. J. C., Postma, A., Peters, M., Hamaker, E. L., Woertman, L., \& Van der Hart, O. (2002). Perceptual and conceptual priming in patients with dissociative identity disorder. Memory \& Cognition, 30, 1033-1043.

Huntjens, R. J. C., Postma, A., Peters, M., Woertman, L., \& Van der Hart, O. (2003). Interidentity amnesia for neutral, episodic information in dissociative identity disorder. Journal of Abnormal Psychology, 112, 290-297.

Huntjens, R.J.C., Postma, A., Peters, M., Woertman, L., \& Van der Hart, O. Memory transfer for trauma-related words between identities in Dissociative Identity Disorder. Manuscript submitted for publication.

Ludwig, A. M., Brandsma, J. M., Wilbur, C. B., Benfeldt, F., \& Jameson, D. H. (1972). The objective study of a multiple personality. Archives of General Psychiatry, 26, 298-310.

Merckelbach, H., Rassin, E., \& Muris, P. (2000). Dissociation, schizotypy, and fantasy proneness in undergraduate students. Journal of Nervous and Mental Disease, 188, 428-431.

Nijenhuis, E. R. S., \& Van der Hart, O. (1999). Forgetting and reexperiencing trauma. In J. Goodwin, \& R. Attias (Eds.), Splintered reflection: Images of the body in trauma (pp. 39-65). New York: Basic Books.

Nijenhuis, E. R. S., Van der Hart, O., \& Steele, K. (2002). The emerging psychobiology of trauma-related dissociation and dissociative disorders. In H. D'haenen, J. A. den Boer, \& P. Willner, (Eds.), Biological psychiatry (pp. 1079-1098). Chichester: Wiley.

Nissen, M. J., Ross, J. L., Willingham, D. B., Mackenzie, T. B., \& Schacter, D. L. (1988). Memory and awareness in a patient with multiple personality disorder. Brain and Cognition, 8, 117-134.

Peters, M. L., Uyterlinde, S. A., Consemulder, J., \& Van der Hart, O. (1998). Apparent amnesia on experimental memory tests in dissociative identity order: An exploratory study. Consciousness and Cognition, 7, $27-41$.

Putnam, F. W. (1997). Dissociation in children and adolescents. New York: The Guilford Press.

Ross, C. A. (1997). Dissociative identity disorder: Diagnosis, clinical features, and treatment of multiple personality (d ed.). New York: Wiley.

Silberman, E. K., Putnam, F. W., Weingartner, H., Braun, B. G., \& Post, R. M. (1985). Dissociative states in multiple personality disorder: A quantitative study. Psychiatry Research, 15, 253-260. 
Steinberg, M. M. D. (1993). Structured Clinical Interview for DSM-IV Dissociative Disorders (SCID. Washington, DC: American Psychiatric Press.

Verhage, F. (1964). Intelligentie en leeftijd: Onderzoek bij Nederlanders van twaalf tot zevenenzeventig jaar [Intelligence and age: Study with Dutch people from age 12 to 77]. Assen, The Netherlands: Van Gorcum.

Yazuv, H. S. (1963). The retention of incidentally learned connotative responses. Journal of Psychology, 55, 409-418. 